\title{
PENERAPAN MESIN SORTASI DALAM UPAYA EFESIENSI PROSES PRODUKSI KOPI GAYO SEBAGAI PRODUK UNGGULAN DAERAH ACEH TENGAH
}

\author{
Indra Mawardi ${ }^{1}$, Hanif $^{2}$, Jannifar ${ }^{3}$, dan Safaruddin ${ }^{4}$ \\ ${ }^{1}$ Jurusan Teknik Mesin, Politeknik Negeri Lhokseumawe \\ Surel: indratm@pnl.ac.id \\ ${ }^{2}$ Jurusan Teknik Mesin, Politeknik Negeri Lhokseumawe \\ Surel: hanifrazak63@gmail.com \\ ${ }^{3}$ Jurusan Teknik Mesin, Politeknik Negeri Lhokseumawe \\ Surel: ajannifar@gmail.com \\ ${ }^{4}$ Jurusan Tata Niaga, Politeknik Negeri Lhokseumawe \\ Surel: safar12@yahoo.com
}

\begin{abstract}
Gayo coffee is a superior regional product in the Central Aceh district. The production process of Gayo coffee is still done traditionally. In developing the quality and quantity of Gayo coffee, it is necessary to apply the production process technology. PKM activity partner, CV. Aceh nutrition has problems in the production process, especially in the sorting process, which is still manual. This process requires labor and long processing time so that the production process becomes inefficient. This problem is essential to be resolved in an effort to increase partner productivity. This service activity aims to improve the efficiency of the coffee bean production process through the application of a green bean sorting machine. The sorting machine will produce green beans based on size or dimensions following SNI. Solving partner problems is carried out using functional and structural approaches. Activities started from problem identification, design, and fabrication of green bean sorting machines, implementation and training, assistance, and evaluation. The results of these activities, green bean coffee sorting machines have been successfully fabricated with a capacity of 200-300 kg/hour. This machine has been implemented to partners CV. Nutrisi Aceh. The green bean sorting machine implemented to partners can operate well. The resulting large green beans amount to $30-40 \%$ of the total sorted green beans. The use of a sorting machine can increase the efficiency of time and labor in the green bean sorting process so that partner productivity can increase.
\end{abstract}

Keywords: Gayo Coffee, Regional Superior Product, Production Process Efficiency, Green Bean Sorting Machine

\begin{abstract}
ABSTRAK
Kopi Gayo merupakan produk unggulan daerah kabupaten Aceh Tengah. Proses produksi kopi Gayo masih banyak dilakukan secara tradisional. Dalam pengembangan kualitas dan kuantitas kopi Gayo diperlukan penerapan teknologi proses produksi. Mitra kegiatan PKM, CV. Nutrisi Aceh memiliki permasalahan dalam proses produksi, khususnya pada proses penyortiran yang masih manual. Proses ini membutuhkan tenaga kerja dan waktu proses yang lama, sehingga proses produksi menjadi tidak efesien. Permasalahan ini menjadi penting untuk diselesaikan dalam upaya peningkatan produktivitas mitra. Tujuan kegiatan pengabdian ini adalah meningkatkan efesiensi proses produksi biji kopi melalui penerapan mesin sortasi green bean. Mesin sortasi akan menghasilkan green bean berdasarkan besar atau dimensi sesuai dengan SNI. Penyelesaian permasalahan mitra dilakukan dengan metode pendekatan fungsional dan struktural. Kegiatan dimulai dari identifikasi permasalahan, perancangan dan fabrikasi mesin sortasi green bean, implementasi dan pelatihan, pedampingan, dan evaluasi. Dari hasil kegiatan telah berhasil difabrikasi mesin sortir green bean kopi dengan kapasitas 200-300 kg/jam. Mesin ini telah diimplemetasikan kepada mitra CV. Nutrisi Aceh. Mesin sortasi green bean yang diimplementasikan kepada mitra dapat beroperasi dengan baik. Green bean ukuran besar yang dihasilkan berjumlah 30-40\% dari jumlah green bean keseluruhan biji kopi yang disortir. Penggunaan mesin sortir dapat meningkatkan efesiensi waktu dan tenaga kerja dalam proses penyortiran green bean sehingga produktivitas mitra dapat meningkat.
\end{abstract}

Kata Kunci: Kopi Gayo, Produk Unggulan Daerah, Efesiensi Proses Produksi, Mesin Sortir Green Bean

\section{PENDAHULUAN}

Kopi adalah salah satu hasil komoditi perkebunan yang memiliki nilai ekonomis yang tinggi selain dari hasil perkebunan lainnya. Kopi berperan penting sebagai sumber devisa negara dan juga 
merupakan sumber penghasilan bagi tidak kurang dari satu setengah juta jiwa petani kopi di Indonesia (Rahardjo, 2012).

Aceh adalah salah satu dari lima provinsi penghasil kopi terbesar di Indonesia selain Sumatera Selatan, Lampung, Sumatera Utara dan Jawa Timur. Dengan luas area perkebunan 123,7 ribu Ha, Aceh memberi konstribusi 10,27\% dari total produksi kopi nasional (Statistik, 2018). Sebagian besar kopi yang dihasilkan oleh provinsi Aceh berasal dari kabupaten Aceh Tengah, Bener Meriah, dan Gayo Lues. Ketiga kabupaten tersebut berada di dataran tinggi Gayo dan pada umumnya menghasilkan kopi Arabika atau yang lebih dikenal dengan kopi Gayo.

Aceh Tengah yang secara geografis berada di dataran tinggi Gayo memiliki luas perkebunan kopi 49.677 Ha dengan produksi mencapai 31.812 ton. Tanaman kopi jenis Arabika mendominasi perkebunan kopi di Aceh Tengah dengan luas $48.701 \mathrm{Ha}(98 \%)$ dan sisanya merupakan kopi jenis kopi Robusta (Tengah, 2017). Bagi masyarakat Kabupaten Aceh Tengah, kopi identik dengan kehidupan, karena sebagian besar penduduk di wilayah dataran tinggi ini menggantungkan hidupnya dari komoditas kopi.

Produk kopi Kabupaten Aceh Tengah Provinsi Aceh telah memperoleh sertifikat Indikasi Geografis (IG) yang diberi oleh Menteri Hukum dan HAM RI pada 27 Mei 2010. Dengan perolehan sertifikat indikasi geografis itu, tentunya sebuah tantangan besar bagi pemerintah dan masyarakat, khususnya petani dari ketiga kabupaten penghasil Kopi Gayo untuk meningkatkan produksinya dimasa mendatang. Hal ini berarti secara otomatis telah memberikan pengakuan kepada komoditi Kopi Gayo sebagai Produk Unggulan Daerah Aceh. Dengan potensi dan peluang bisnis kopi Gayo ini tentunya yang akan membawa dampak besar bagi petani kopi Gayo dan juga perekonomian Aceh. Untuk itu para UKM dan petani kopi harus tetap menjaga kualitas kopi dan membangun kepercayaan konsumen. Hal ini diperkuat di rencana pembangunan jangka menengah (RPJM) kabupaten Aceh Tengah. Dalam RPJM Kabupaten Aceh Tengah Tahun 2017-2022, kopi menjadi prioritas pertama sebagai komoditi unggulan. Nilai ekspor komoditi kopi ditargetkan pada tahun 2022 mencapai 148.800.000 USD (Takengon, 2018).

Dalam rangka penguatan produk unggulan daerah kabupaten Aceh Tengah, tim kegiatan Program Pengembangan Produk Unggulan Daerah (PPPUD) Politeknik Negeri Lhokseumawe bermitra dengan CV. Nutrisi Aceh. CV. Nutrisi Aceh adalah UMKM produsen kopi dipimpin oleh Bapak M. Rasid A sebagai pemilik utama dan berdiri tahun 2008. Mitra adalah petani dan juga produsen green bean (biji kopi beras) Gayo jenis specialty. Green bean speciality dijual dengan harga Rp. 170.000 - Rp. 180.000,- per kg. Mitra beralamat di Desa Tawar Miko Kecamatan Kute Panang Kabupaten Aceh Tengah. Dalam menghasilkan produknya, mitra mempunyai lahan kopi seluas 5 Ha yang dikelola secara intensifikasi.

Dalam proses produksi green bean, mitra melakukan beberapa tahapan proses, yaitu: proses panen buah merah, sortir dimensi buah merah, sortir kualitas buah merah, pengupasan kulit buah kopi, permentasi, pencucian, penjemuran, pengupasan kulit tanduk (hulling), penjemuran, sortir green bean, dan penyimpanan. Proses-proses tersebut masih dilakukan secara konvensional dan masih minim sentuhan teknologi. Dengan kondisi peralatan yang ada, berpengaruh terhadap masih rendahnya efesiensi proses produksi green bean, sehingga sulit meningkatkan jumlah produksi. Mitra hanya dapat memproduksi kapasitas produksi green bean sebanyak 2-3 ton per tahun. Ketersedian teknologi pascapanen yang tepat menjadi kendala utama mitra dalam meningkatkan produktivitas. Mitra sebagai produsen kopi perlu didukung dengan kesiapan teknologi dan sarana pascapanen yang tepat. Hal ini didukung dari hasil penelitian (Mayrowani, 2013), yang menyatakan ketersedian teknologi yang cocok, ketersediaan dalam jumlah yang cukup dan 
pasokan yang tepat waktu serta keberlanjutan merupakan beberapa persyaratan yang dibutuhkan agar biji kopi dapat dipasarkan pada tingkat harga yang lebih menguntungkan.

Keberhasilan agribisnis kopi membutuhkan dukungan semua pihak yang terkait dalam proses produksi (pengolahan dan pemasaran). Berbagai upaya terus dilakukan untuk meningkatkan produktivitas dan mutu kopi melalui teknologi proses sehingga daya saing kopi di Indonesia dapat bersaing di pasar dunia. Pengolahan kopi sangat berperan penting dalam menentukan kualitas dan cita rasa kopi. Peningkatan produksi kopi di Indonesia masih terhambat oleh rendahnya mutu biji kopi yang dihasilkan sehingga mempengaruhi pengembangan produksi akhir kopi. Hal ini tidak terlepas dari penanganan pasca panen yang tidak tepat antara lain proses fermentasi, pencucian, sortasi, pengeringan, dan penyangraian. Disamping itu, spesifikasi alat/mesin yang digunakan juga dapat mempengaruhi setiap tahapan pengolahan biji kopi. Oleh karena itu, untuk memperoleh biji kopi yang bermutu baik maka diperlukan penanganan pascapanen yang tepat dengan melakukan setiap tahapan secara benar (Rahardjo, 2012).

Mitra kegiatan CV. Nutrisi Aceh sebagai produsen kopi menghadapi permasalahan dalam proses penyortiran green bean. Proses sortasi green bean merupakan proses yang penting dari serangkaian proses produksi kopi siap jual. Proses sortasi green bean dilakukan untuk mengklasifikasi biji kopi berdasarkan dimensi. Dimensi biji kopi yang dikategorikan berbentuk besar, sedang dan kecil sangat berpengaruh terhadap nilai jual. Proses sortir yang dilakukan oleh mitra selama ini masih secara manual dengan memilih biji kopi dengan tangan dan menggunakan peralatan yang sederhana (Gambar 1). Proses ini membutuhkan waktu dan pekerja yang lebih banyak. Kondisi ini sangat tidak efesien dalam proses produksi. Pada tahun pertama, salah satu kegiatan PKM di CV. Nutrisi Aceh adalah penerapan mesin sortasi biji kopi (green bean).

Tujuan dari program PKM adalah meningkatkan efesiensi proses produksi biji kopi melalui penerapan mesin sortasi green bean. Mesin sortasi akan menghasilkan green bean berdasarkan besar atau dimensi sesuai dengan SNI.

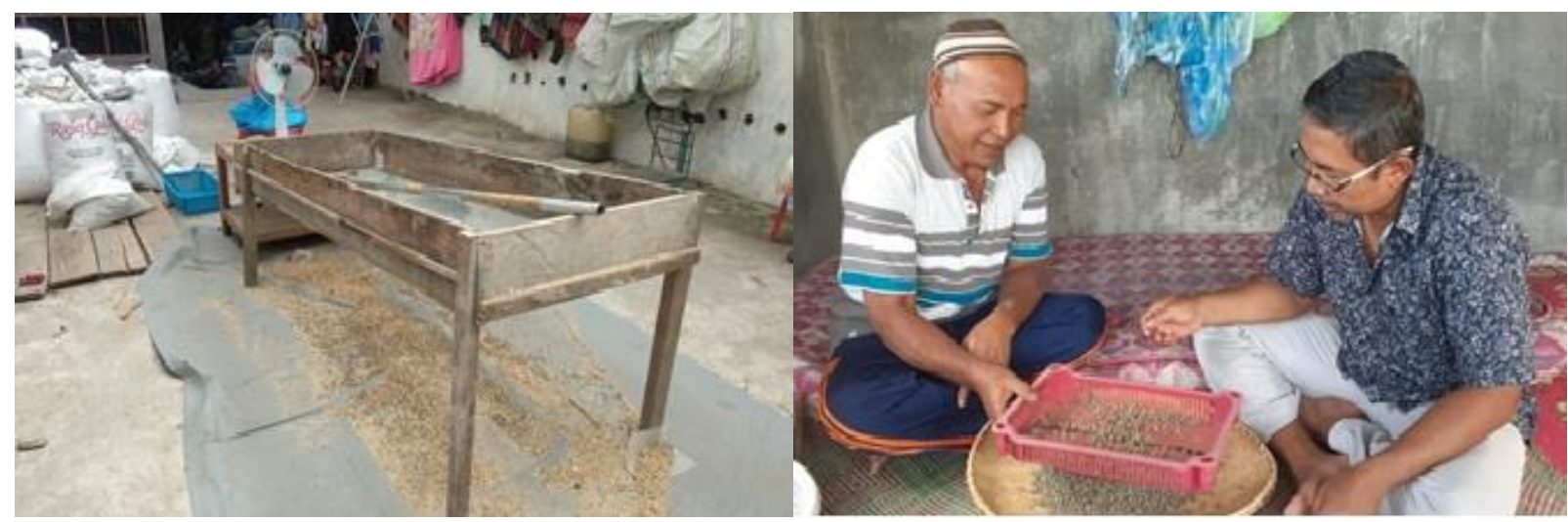

Gambar 1. Proses Sortir Green Bean di Mitra

Sumber: Penulis, 2019

Secara umum, cara pengolahan kopi terbagi dua cara, yaitu pengolahan kering dan pengolahan basah. Pengolahan kering, dimana hasil panen langsung dijemur selama 10-14 hari. Buah kopi yang sudah kering kemudian disimpan sebagai kopi glondongan. Kopi glondongan ditumbuk untuk melepas biji dari kulit arinya jika ingin dijual. Tahapan pascapanen kopi secara kering dapat dilihat pada Gambar 2. 


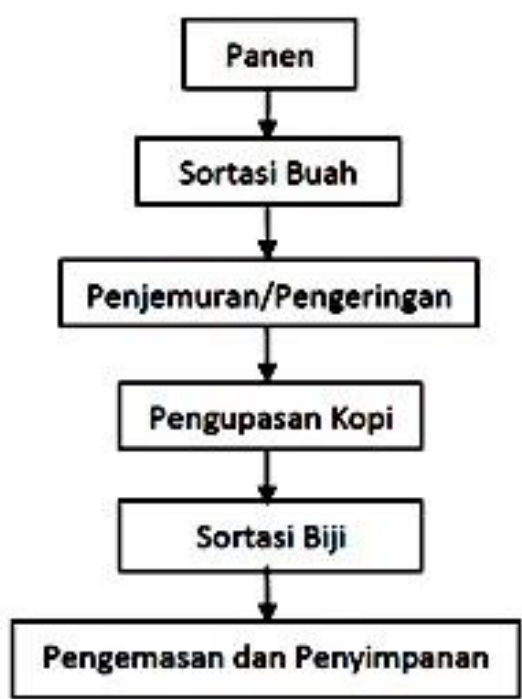

Gambar 2. Tahapan Pascapanen Kopi Secara Kering

Tahapan proses kopi secara basah dapat dilihat pada Gambar 3. Prinsip dasar pengolahan basah adalah menghilangkan lendir dari buah kopi dimana senyawa gula yang terkandung di dalam lendir memiliki sifat higroskopis (menyerap air). Permukaan biji kopi yang cenderung lembab akan menghalangi proses pengeringan yang dapat berakibat terjadinya kontaminasi. Bakteri tumbuh pada permukaan kopi akibat adanya senyawa gula pada permukaan biji kopi.

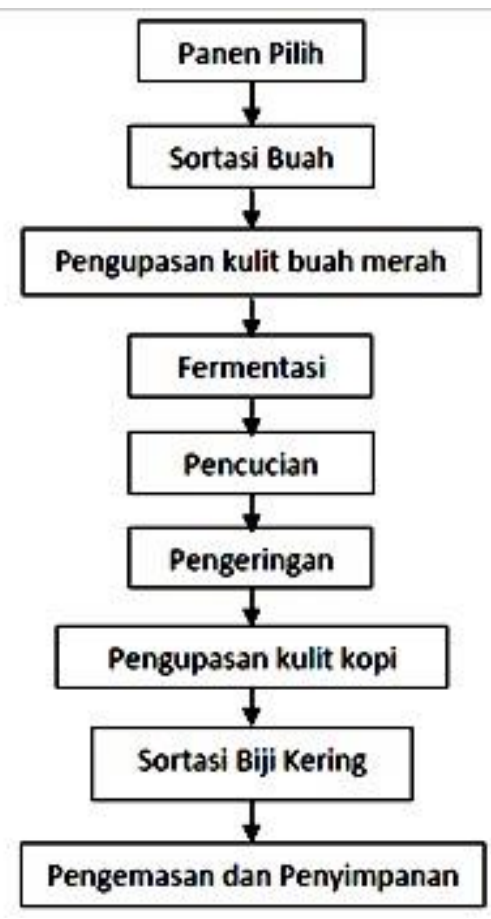

Gambar 3. Tahapan Pascapanen Kopi Secara Basah

Proses pascapanen kopi seperti pengupasan kulit buah kopi, pencucian, pengupasan kulit HS dan sortasi telah banyak dilakukan dengan mesin-mesin teknologi tepat guna. Penerapan teknologi tepat guna pascapanen kopi merupakan salah satu cara untuk meningkatkan efesiensi proses produksi green bean kopi Gayo. Beberapa peneliti telah mengembangkan mesin-mesin TTG pascapanen kopi, seperti (Indra Mawardi, Hanif, 2017) dan (Mawardi, Hanif, Zaini, \& Abidin, 2019) yang telah merancang dan memproduksi mesin pengupas kulit buah kopi berjalan, mesin 
huller berjalan. (Mawardi, 2018), (Mawardi, Nurdin, \& Zulkarnaini, 2020), (Muzammir, Mawardi, \& Bahri, 2018) telah mempublikasikan mesin-mesin teknologi tepat guna pascapanen kopi dan implementasikan kepada petani kopi di kabupaten Bener Meriah.

Kopi hasil perkebunan Indonesia yang mempunyai daya saing tinggi di pasar internasional. Namun, perkebunan kopi di Indonesia memiliki produktivitas yang rendah dibandingkan negaranegara produsen utama kopi lainnya. (Zen \& Budiasih, 2018) meneliti produktivitas dan efisiensi teknis usaha perkebunan kopi di Sumatera Selatan dan Lampung.. Hasil penelitian ini menunjukkan bahwa lebih dari 50\% usaha perkebunan kopi di masing-masing provinsi tersebut memiliki produktivitas rendah dan efisiensi teknis menengah.

(Risandewi, 2013) melakukan analisis efisiensi produksi kopi robusta di kabupaten Temanggung kecamatan Candiroto. Hasil penelitiannya menyatakan cara meningkatkan efisiensi produksi kopi robusta untuk masing-masing petani di Kecamatan Candiroto adalah dengan dengan cara mengurangi jumlah tenaga kerja yang tidak diperlukan, peremajaan umur kopi robusta, mengurangi jumlah pupuk agar tidak berlebihan sehingga mengurangi kesuburan tanah, intensifikasi lahan.

Proses produksi adalah kegiatan yang mengkombinasikan input (sumber daya) untuk menghasilkan output dalam suatu usaha atau proses perubahan dari input menjadi output untuk menghasilkan dan menambah nilai suatu barang Dalam kaitannya dengan pertanian, produksi merupakan esensi dari suatu perekonomian. Untuk berproduksi diperlukan sejumlah input, dimana umumnya input yang diperlukan pada sektor pertanian adalah adanya kapital, tenaga kerja, tanah atau sumber daya alam dan teknologi.

Peningkatan efisiensi sangat penting dalam rangka peningkatan keuntungan dan daya saing. Peningkatan efisiensi dan produktivitas usaha tani kopi dapat dilakukan dengan menggunakan teknologi yang ada dengan baik, menggunakan jumlah input yang optimal dan memilih skala usaha yang optimal. Efisiensi produksi berkaitan dengan produksi barang dan jasa dengan kombinasi input yang optimal untuk menghasilkan output maksimum dengan biaya minimum.

\section{METODE PELAKSANAAN PKM}

Penyelesaian permasalahan mitra dilakukan dalam dua metode, yaitu: metode pendekatan fungsional dan struktural. Metode pendekatan fungsional dalam bentuk identifikasi permasalahan, implementasi, pendampingan dan evaluasi. Metode struktural berupa perancangan dan fabrikasi mesin sortasi green bean. Langkah-langkah pelaksanaan kegiatan, antara lain:

a. Identifikasi permasalahan dan kebutuhan mitra.

Permasalahan awal yang harus diselesaikan adalah meningkatkan efesiensi proses produksi pada penyortiran green bean.

b. Perancangan dan fabrikasi mesin sortasi green bean.

- Rancangan sortasi green bean

Cara sortasi biji adalah dengan memisahkan biji-biji kopi secara dimensi ukuran Mesin sortasi dirancang dengan tiga tingkatan ayak, yaitu; besar, sedang dan kecil sesuai dengan ketentuan SNI 01-2907-2008. Mesin sortasi menggunakan motor bakar bensin 3,5 Hp. Prinsip kerja mesin sortasi adalah gerakan translasi yang dihasilkan dari poros engkol. Mesin menggunakan gear box reducer sebagai penurun putaran mesin ke poros engkol. Mesin sortasi dirancang dengan dimensi 1800x1000x1200mm. Gambar 4 memperlihatkan rancangan mesin sortasi green bean. 


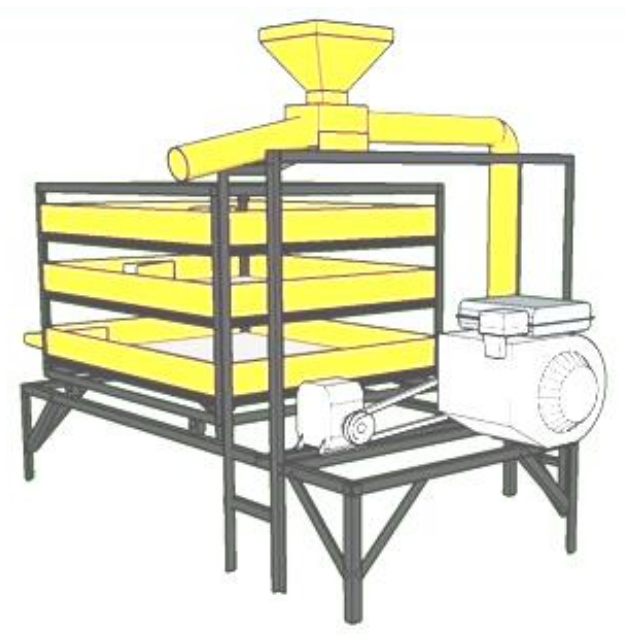

Gambar 4. Rancangan Mesin Sortasi Green Bean

Sumber: Penulis, 2020

- Fabrikasi mesin sortasi green bean

Fabrikasi mesin sortasi dilakukan di Jurusan Teknik Mesin di Politeknik Negeri Lhokseumawe. Konstruksi mesin sortasi menggunakn besi UNP, besi siku, pelat mild stell, dan beberapa komponen standar seperti puli, sabuk, roller, gearbox reducer dan motor bakar bensin. Peralatan yang digunakan terdiri dari mesin gerinda potong, gerinda tangan, mesin las dan alat ukur.

c. Implementasi dan pelatihan.

Mesin mesin sortasi green bean yang telah difabrikasi kemudian dilakukan implementasi di lokasi mitra. Mitra diberi pelatihan teknik mengoperasikan dan perawatan mesin. Pada kegiatan ini dilakukan evaluasi kemampuan mitra dalam mengoperasikan mensin.

d. Pedampingan

Pendampingan diberikan guna mengatasi permasalahan yang terjadi selama penerapan teknologi ke mitra.

e. Evaluasi

Evaluasi dilakukan secara berkala untuk melihat ketercapaian program dan berguna untuk melihat tingkat keberlanjutan kegiatan nantinya.

\section{HASIL DAN PEMBAHASAN}

Selain dalam bentuk bubuk, buah kopi biasanya dipasarkan dalam bentuk biji kopi beras (green bean), yaitu kopi kering yang sudah dikupas dari daging buah dan kulit arinya. Setelah dikupas, kopi harus disortir untuk memisahkan biji kopi yang baik dari kotoran (sisa kulit tanduk), kulit ari, debu, biji biji inferior, pecah dan sebagainya. Dengan kata lain, proses sortasi green bean merupakan proses pemisahan green bean untuk mendapatkan mutu tertentu yang didasarkan atas sifat-sifat seperti ukuran, bentuk, berat jenis, sifat permukaan, dan warna. Selain itu, tujuan sortasi adalah untuk menentukan grading pada biji kopi.

Sortasi ukuran green bean dapat dilakukan secara manual maupun dengan ayakan mekanis. Sortasi green bean dengan tingkat keragaman yang tinggi jika dilakukan secara manual akan membutuhkan waktu yang lebih lama dan tingkat kelelahan pekerja yang tinggi, sehingga dapat menurunkan produktifitas. Green bean dengan keseragaman ukuran, bebas dari kontaminasi unsur pengotor dan jumlah cacat yang kecil akan mempengaruhi harga jual dari dari green bean itu sendiri. Bagi konsumen, keseragaman ukuran biji, bersih dari unsur-unsur lain merupakan salah satu aspek dari mutu biji kopi yang sangat penting. Keseragaman green bean dan tidak 
terkontaminasi unsur lain akan berpengaruh pada proses produksi kopi, yaitu penyangraian. Proses penyangraian menuntut keseragaman biji kopi agar pemasakan yang terjadi dapat merata sehingga hasilnya mempunyai kualitas yang lebih baik. Gambar 5 memperlihatkan mesin sortasi green bean yang telah selesai difabrikasi. Mesin ini bertujuan memisahkan green bean berdasarkan ukuran.

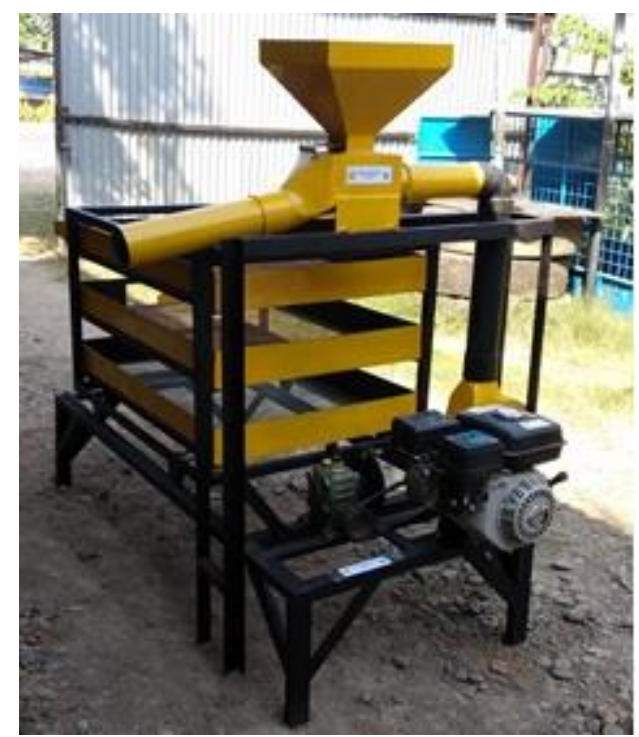

Gambar 5. Mesin Sortasi Biji Kopi (Green Bean)

Sumber: Penulis, 2020

Proses sortir ini akan memberikan dampak yang efektif dalam meningkatkan efesiensi kerja dalam proses produksi kopi sehingga dapat meningkatkan nilai jual green bean mitra nantinya. Pemisahan green bean mengacu pada persyaratan khusus SNI 01-2907-2008 (Tabel 1).

Tabel 1. Syarat mutu khusus kopi Arabika

\begin{tabular}{|c|l|c|}
\hline \multicolumn{1}{|c|}{ Ukuran } & \multicolumn{1}{c|}{ Kriteria } & \multicolumn{1}{c|}{ Persyaratam } \\
\hline Besar & Tidak lolos ayakan berdiameter 6,5 mm (sieve No. 16) & Maksimal lolos 5\% \\
\hline Sedang & $\begin{array}{l}\text { Lolos ayakan berdiameter 6,5 mm, tidak lolos ayakan berdiameter 6 } \\
\text { mm (sieve No.15) }\end{array}$ & Maksimal lolos 5\% \\
\hline Kecil & $\begin{array}{l}\text { Lolos ayakan berdiameter 6 mm, tidak lolos ayakan berdiameter 5 } \\
\text { mm (sieve No. 13) }\end{array}$ & Maksimal lolos 5\% \\
\hline
\end{tabular}

Prinsip kerja mesin sortir dimulai dengan memasukkan green bean yang telah kering hasil dari proses pengupasan kulit tanduk (hulling) ke dalam hopper, dan secara grafitasi green bean akan jatuh dalam bak sortir. Bak sortir bergerak secara translasi dengan kecepatan maju mundur 90 kali per menit. Bak sortir memiliki ayakan tingkat pertama dengan diameter lubang $6.5 \mathrm{~mm}$ dan ayakan tingkat kedua dengan diameter $4 \mathrm{~mm}$. Biji kopi yang tidak lolos pada tingkat pertama dapat dikategorikan green bean ukuran besar. Sedangkan yang lolos dari tingkat pertama tetapi tidak lolos pada tingkatan kedua dikategorikan green bean ukuran sedang. Green bean yang lolos pada tingkatan kedua dikategorikan ukuran kecil. 
Mesin sortasi green bean yang diimplementasikan kepada mitra dapat beroperasi dengan baik. Dari hasil penyortiran, green bean terklasifikasi berdasarkan ukuran ayakan. Hasil sortiran green bean ukuran besar yang tidak lolos pada lubang berdiameter 6,5 diperlihatkan pada Gambar 6 . Green bean ukuran besar yang dihasilkan berjumlah 30-40\% dari jumlah green bean keseluruhan yang disortir.

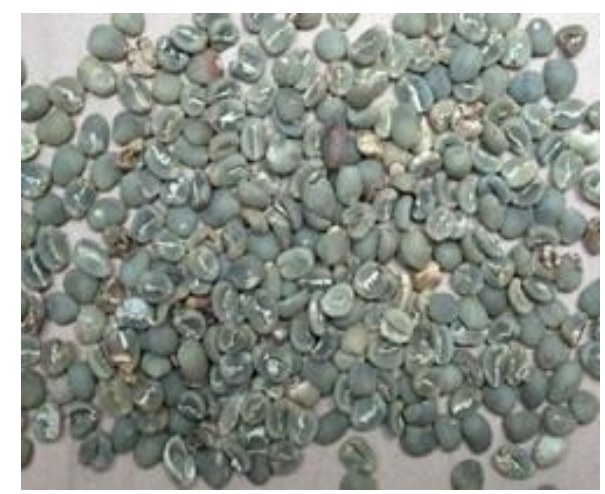

Gambar 6. Green Bean Ukuran Besar

Sumber: Penulis, 2020

Gambar 7 memperlihatkan green bean ukuran sedang. Green bean ukuran sedang didapat dari biji kopi yang lolos pada ayakan berdiameter $6,5 \mathrm{~mm}$ dan tidak lolos ayakan diameter $4 \mathrm{~mm}$. Sedangkan hasil sortiran ukuran kecil didapat dari green bean yang lolos dari ayakan berdiameter 4 (Gambar 8).

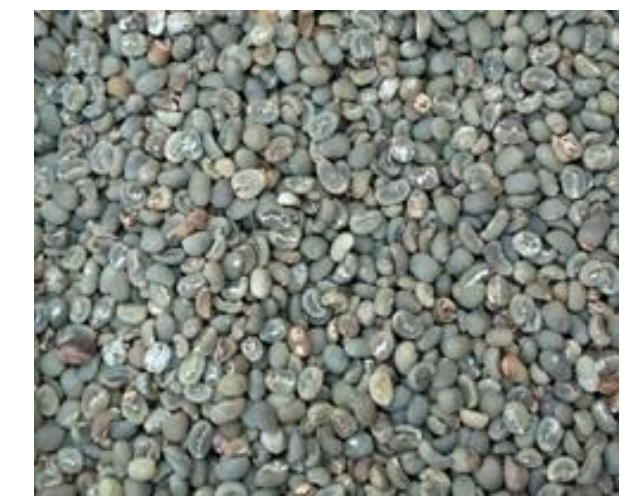

Gambar 7. Green Bean Ukuran Sedang

Sumber: Penulis, 2020

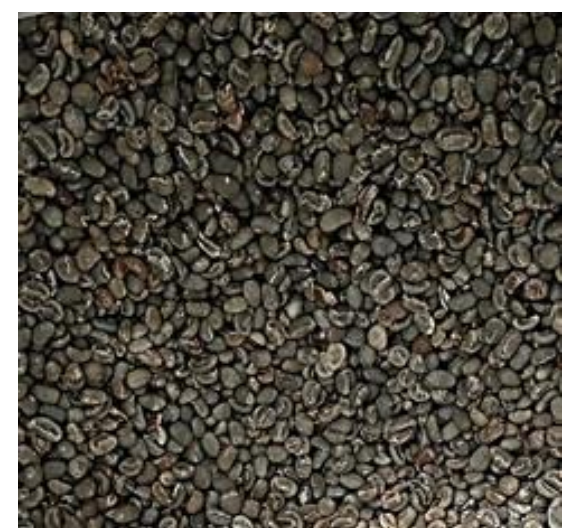

Gambar 8. Green Bean Ukuran Kecil

Sumber: Penulis, 2020 
Dari hasil penyortiran biji kopi green bean, biji kopi dapat tersortir dengan baik, hal ini diperlihatkan dengan terpisahnya ukuran-ukuran dari biji kopi dengan ukuran besar, sedang dan kecil. Mesin sortir yang diimplentasikan kepada mitra memiliki kapasitas sortir green bean 200$300 \mathrm{~kg} / \mathrm{jam}$. Proses penyortiran yang dilakukan mitra secara manual membutuhkan 4-5 orang dengan lama penyortiran sekitar 4-5 jam untuk green bean sebanyak $200 \mathrm{~kg}$. Jika dibandingkan dengan manual, penggunaan teknologi mesin sortir dapat meningkatkan efesiensi kerja dan waktu. Penyortiran menggunakan mesin hanya membutuhkan 1 orang tenaga kerja dengan waktu yang relatif lebih cepat.

\section{KESIMPULAN DAN SARAN}

Dari hasil kegiatan, telah berhasil difabrikasi dan diimplemetasikan teknologi mesin sortir green bean dalam upaya penyelesaian permasalahan proses penyortiran green bean pada mitra, CV. Nutrisi Aceh. Mesin sortir green bean dapat berfungsi dengan baik dan dapat memisahkan green bean berdasarkan ukuran. Mesin sortir green bean memiliki kapasitas 200-300 kg/jam. CV. Nutrisi Aceh telah dapat meningkatkan efesiensi proses produksi kopi khususnya green bean, berupa efesiensi waktu dan tenaga kerja dalam proses penyortiran green bean. Ketersediaan mesin sortasi green bean secara tidak langsung telah dapat meningkatkan produktivitas dan ekonomi mitra.

\section{Ucapan Terima Kasih (Acknowledgement)}

Terimakasih kepada Kementerian Riset dan Teknologi/Badan Riset dan Inovasi Nasional yang telah membiayai program PKM dengan skim Program Pengembangan Produk Unggulan Daerah (PPPUD) Tahun 2019 dan Politeknik Negeri Lhokseumawe yang telah mendukung fasilitas pelaksanaan kegiatan.

\section{REFERENSI}

Indra Mawardi, Hanif, Z. (2017). Inovasi Mesin-mesin Teknologi Tepat Guna Pascapanen Kopi. In sendimas 2017 (pp. 6-11). Bandung: univeristas maranatha. Retrieved from https://sendimas.maranatha.edu/index.php/2017/2017/paper/viewFile/57/58

Mawardi, I. (2018). Inovasi TTG Mesin Huller Kopi Multi Fungsi Dalam Upaya Peningkatan Pascapanen Kopi. In Seminar Nasional hasil Pengabdian kepada Masyarakat (SENDIMAS) $\mathrm{Ke}-4$.

Mawardi, I., Hanif, H., Zaini, Z., \& Abidin, Z. (2019). Penerapan Teknologi Tepat Guna Pascapanen Dalam Upaya Peningkatan Produktifitas Petani Kopi di Kabupaten Bener Meriah. CARADDE: Jurnal Pengabdian Kepada Masyarakat, 1(2), 205-213.

Mawardi, I., Nurdin, N., \& Zulkarnaini, Z. (2020). INOVASI MESIN-MESIN TEKNOLOGI PASCAPANEN KOPI SEBAGAI PRODUK USAHA INTELEKTUAL KAMPUS POLITEKNIK NEGERI LHOKSEUMAWE. Panrita Abdi-Jurnal Pengabdian Pada Masyarakat, 4(1), 24-33.

Mayrowani, H. (2013). Kebijakan penyediaan teknologi pascapanen kopi dan masalah pengembangannya. In Forum Penelitian Agro Ekonomi (Vol. 31, pp. 31-49).

Muzammir, M., Mawardi, I., \& Bahri, S. (2018). MODIFIKASI KONSTRUKSI MESIN PENGUPAS KULIT ARI KOPI DENGAN DAYA 5 HP. Jurnal Mesin Sains Terapan, 2(2), 62-65.

Rahardjo, P. (2012). Panduan Budidaya dan Pengolahan Kopi Arabika dan Robusta. Penebar Swadaya. Jakarta. 
Risandewi, T. (2013). Analisis efisiensi produksi kopi robusta di kabupaten temanggung. Sumber, $31,1-485$.

Statistik, B. P. (2018). Statistik Kopi Indonesia. Badan Pusat Statistik. Jakarta.

Takengon, P. K. A. T. Qanun Kabupaten Aceh Tengah Nomor 3 Tahun 2018 tentang Rencana Pembangunan Jangka Menengah Daerah (RPJMD) Kabupaten Aceh Tengah Tahun 20172022 (2018). Indonesia.

Tengah, B. P. S. K. A. (2017). Kabupaten Aceh Tengah Dalam Angka.

Zen, F., \& Budiasih, B. (2018). Produktivitas dan Efisiensi Teknis Usaha Perkebunan Kopi di Sumatera Selatan dan Lampung. Jurnal Ekonomi Dan Pembangunan Indonesia, 72-86. 